\title{
2019 ALA Annual Conference Updates
}

\section{Awards Committee}

GODORT honored the recipients of its 2019 awards at the annual GODORT Awards Reception at the George Washington University Jacob Burns Law Library's Tasher Great Room on Sunday, June 23, 2019, 6:00-8:00 p.m. Recipients of the awards include:

\section{ProQuest/GODORT/ALA “Documents} to the People” Award: Laura Harper

\section{Bernadine Abbott Hoduski Founders}

Award: Kris Kasianovitz

\section{Margaret T. Lane / Virginia F. Saun-} ders Readex Memorial Research Award: Government Information Essentials, edited by Susanne Caro, authored by Jane Canfield, Susanne Caro, David Dillard, Latanya N. Jenkins, Hayley Johnson, Valery King, Shari Laster, Lori Looney, Andrew Lopez, Leasha E. Martin, Vickie Mix, Lisa Pritchard, Aimee C. Quinn, Antoinette W. Satterfield, Julia Steward, Jill Vassilakos-Long, and Paula L. Webb.

Newsbank/Readex/GODORT/ALA Catharine J. Reynolds Research Grant: Hayley Johnson

\section{W. David Rozkuszka Scholarships:} Ben Chiewphasa and Lauren Hall

\section{ALA/GODORT Emerging Leader: Azalea Ebbay}

GODORT/Rainbow Roundtable Larry Romans Mentorship Award: July Siebecker

The Awards Committee met in a closed session at the ALA Annual Conference to discuss the reception plans, the previous year's work, and the outlook for the next year's committee work. An opportunity arose in November 2018 for the Rozkuszka Scholarship to be listed in the ALA Scholarship Clearinghouse for 2019 for the 2020 award. While this move will change the date for the deadline of the Rozkuszka applications from December 1, 2019, to a date in March, 2020, the committee agreed that the increased publicity for the award and potential increase in applications would be worth the change. The selection of the recipient will be made in time for the June 2020 GODORT Awards reception at Annual Conference.-Emily Rogers

\section{Cataloging Committee}

The GODORT Cataloging Committee met on Sunday, June 23, 2019, at the Mariott Marquis, Supreme Court room. All Committee members attended. A Zoom meeting was available for virtual members and guests. Chair, Andrea Morrison, called the meeting to order and welcomed guests. Andrea Craley, incoming Chair, volunteered to take the minutes. Guest Paige Andrews volunteered to run the Zoom meeting and report comments. Approval of previous minutes was postponed until after conference. Donna Kraemer, incoming GPO representative, gave the Library Services and Content Management update. The Committee had questions about the use of Z39.50 cataloging records from CGP and the National Institute of Standards and Technology (NIST) cataloging record set. The chair urged everyone present to submit comments on GPO cataloging via askGPO. Jim Noel, Marcive, distributed the Marcive report before the meeting. Andrea Morrison gave the CC:DA liaison report on the activities of the Committee on Cataloging: Description and Access (CC:DA, https://alcts.ala.org/ ccdablog/). The restructured cataloging standard RDA: Resource Description and Access will be released in 2020 (see RDA Toolkit, beta RDA, at https://www .rdatoolkit.org/). A written report will follow. The main topic of discussion was the Cataloging Toolboxes LibGuides, listed under the Cataloging group on the GODORT LibGuides page, https:// godort.libguides.com. Andrea Morrison, chair of the Cataloging Toolboxes Working Group, released the draft Cataloging Toolboxes for U.S. Federal Government Information and International Government Information to the public with "under construction" notifications and reported on the progress of the project. The Committee approved publishing the Toolboxes and asking for crowdsource editing. Andrea will send the announcements after conference. Simon Healey agreed to review the LibGuides for accessibility. The Cataloging Toolbox for State and Local Government Information is currently in progress and unpublished. Volunteer contributions and editing is needed for all Toolboxes. State government information is needed for each state, including state library catalogs, classification, cataloging manuals and cataloging manuals. Working Group member Edith Beckett will contribute New Jersey state information and assist Simon on accessibility. Michael Alguire commented on educational outreach for cataloging. The Committee agreed by consensus to focus on improving the LibGuides as the first priority. Finally, the Committee discussed GODORT's draft recommendations on Equity, Diversity, and Inclusions and recommended that the Cataloging Committee discuss issues of equity, diversity, and inclusion (EDI) related to the ethics of cataloging, metadata description, and changing subject vocabularies. All GODORT groups should seek to include EDI topics 
related to their activities in their ongoing work.-Andrea Morrison, GODORT Cataloging Committee past chair

\section{Education Committee}

The Education Committee continued its discussion around two continuing projects related to the government information education of current and future library professionals. First, the Emerging Leaders team-comprising Azalea Ebbay, Shelly Guerrero, Megan HamlinBlack, and Leslie Purdie-presented a summary of their sixteen-page report on a Librarians' Elections and Voting Toolkit. The committee discussed their recommendations, thanked them for their work on the report, and agreed to reach out to contacts with the State Agency Database project to see how best to proceed with creating toolkits and deploying marketing materials for all fifty states. The goal is to have the toolkits ready to go in time for the 2020 election season.

Second, the committee discussed next steps for surveying and promoting government information education in LIS programs. The group discussed previous surveying efforts (most recently in 2007) and agreed that it would be helpful to have an updated survey of gov info courses and instruction in LIS programs to get a sense of how gov info education in LIS programs has changed in the last decade. The committee will be reviewing the current literature on this topic as well.

With two major time-sensitive projects underway, the Education Committee will be looking for times to meet over the summer to continue momentum on these projects.—Kian Flynn

\section{Membership Committee}

GODORT 101 was standing-room only, with attendees reflecting the wide gamut of Government Information
Professionals: Federal, State, and Municipal Agency; State Libraries and Archives; Depository, Law; general and subject-specific reference, Public, Special, digital, i-school professors and administrators, preservation; archivists, e-gov; catalogers; outreach, education and community engagement; vendors; and several divisions of Library of Congress, GPO and the National Archives. Following the session, the group moved to Happy Hour at the Marriott's Marquis' High Velocity Bar.—Rachel Dobkin

\section{GODORT Federal Information Interest Group (FIIG) meeting}

The Federal Information Interest Group (FIIG) met at the 2019 ALA Annual Conference in Washington, D.C., on Saturday, June 22, from 9 to 10 a.m. in the Dogwood Room of the Marriott Marquis Hotel. Forty-one people participated in the meeting.

Three guest speakers, Katrina Stierholz from the St. Louis Federal Reserve, and Stephanie Studds and Adeline Tran from the U.S. Census Bureau, gave presentations showcasing the partnership between the St. Louis Federal Reserve and the U.S. Census Bureau by sharing the data they have and the tools to access it. They shared techniques for incorporating data in the classroom as well as ways that Census is exploring alternative data sources to supplement traditional surveys. FRED (Federal Reserve Bank of St. Louis Economic Data), at https:// fred.stlouisfed.org/ was discussed. FRED usage is up 50 percent, and can be downloaded to a smart phone. FRASER, at https://fraser.stlouisfed.org, is another resource.

Patricia Siska served as FIIG Group Leader 2019. Hayley Johnson is incoming FIIG Group Leader 2020.

\section{Membership Update}

Following introductions and announcements, Treasurer Rebecca Hyde provided a summary on the status of GODORT's finances, with the full report being sent to the GODORT Membership distribution list.

Past-chair and chair of GODORT's Ad Hoc Committee on Equity, Diversity, and Inclusion, Shari Laster, presented this group's final report including recommendations for GODORT. This report was distributed to GODORT's Membership distribution list for feedback regarding implementation of these recommendations. A brief discussion regarding implementation and recommendations was conducted between those present. Shari plans to ask that this be discussed by Steering at a later date.

Bill Sudduth, GODORT's Councilor, provided his report from ALA Council, which had only met once at the time of the GODORT Membership meeting. An additional meeting would take place before the end of Annual Conference with the focus on discussing the Subcommittee on Organizational Effectiveness's recommendations for modifying and streamlining the structure of ALA, including restructuring Round Tables.

Simon Healey, a member of ALA's Conference Committee discussed updates on proposed changes to the Midwinter Meeting model. Midwinter 2020 in Philadelphia will be the last iteration of Midwinter in its current format. For Midwinter 2021, the intention is to have a soft launch of a new Midwinter Meeting structure, with an emphasis on programming and professional development, with few business meetings.

GODORT Chair Hallie Pritchett provided an update on the creation of the new Technology Committee, which currently has three members. She is still 
looking to find a person to fill the position of chair of this committee.

Megan Hamlin-Black, member of the GODORT Emerging Leader's group assigned to create a marketing and implementation plan for a librarianto-librarian election toolkit, gave an overview of their project and their final report. GODORT would like to thank the entire Emerging Leader team, Megan Hamlin-Black, Shelly Guerrero, Azalea Ebbay, and Leslie Purdie, for their wonderful work.-Julia Frankosky, GODORT Secretary

\section{Publications Committee}

At the Publications meeting Katie Cuyler was recognized as the incoming chair, with Michael Smith as chair-elect.

Bryan Fuller agreed to be the Notable Documents chair again, and he is looking for a new State and Local documents selector.

Laura Sare is in the process of getting a new ISSN number for $D t t P$ since it is now online. Statistics for $D t t P$ were shared with the group, and Charmaine Henriques' article "Science, Agriculture, and Nutrition: The Government Documents that Influenced a Nation's Food and Diet" from the Summer 2016 issue had 535 views between the 2019 Midwinter Meeting and Annual Confernce.

Guest Patrice McDermott spoke to the group about how we refer people to NARA resources and how we use the records disposition schedules. She told everyone that you can use the older records disposition schedules to see what kinds of records exist which make it easier to make FOIA requests._Laura Sare

\section{Steering Committee}

Simon Healey, a member from the ALA Conference Committee, explained the new model for the Midwinter Meeting, which will have a soft launch for Midwinter 2021.

Andrew Pace, the ALA Executive Board liaison to GODORT, provided Steering with updates regarding ALA's finances and the Subcommittee on Organizational Effectiveness. The ALA Executive Director search is underway and ALA plans to introduce finalist candidates in October, with the hope of announcing the new director at Midwinter 2020.

Rebecca Hyde, GODORT Treasurer, provided the Treasurer's Report, emphasizing that the market has rebounded and GODORT's finances are in good shape.

Action items from the committees were presented by the committee chairs who were able to attend Steering.

Shari Laster, past-chair of GODORT and current chair of GODORT's Ad Hoc Committee on Equity, Diversity, and Inclusion asked for Steering to endorse in principle the recommendations presented in the EDI report. This motion to endorse in principle passed unanimously.

Program ideas for the 2020 Annual Conference were discussed, as the deadline to submit proposals is September 10, 2019. A current idea is the prison pipeline and examining issues related to disenfranchisement.

Hallie Pritchett, chair of GODORT, discussed the status of the newly created Technology Committee. Three people have volunteered but she is still seeking a chair for this committee, preferably someone with experience with Drupal.

There was additional discussion regarding the future of GODORT's presence at the Midwinter Meeting. While the new program-centric model will not go into effect until Midwinter 2021, GODORT should consider having more programming and fewer meetings at Midwinter 2020. This discussion will continue at the next Steering Committee meeting.

Megan Hamlin-Black, a member of the Emerging Leader's group who worked on a project to create a marketing and implementation plan to create a librarian-to-librarian toolkit for election information, provided an overview of the team's report. Steering was asked to vote to accept their report and offer their thanks to the group. This passed unanimously.

There was a proposal to change the International Documents Task Force to an interest group. After discussion, it was decided that this proposal would be discussed further at the next Steering Committee meeting.-Julia Frankosky, GODORT Secretary

\section{Treasurer Report}

For FY2019 through April 30, GODORT's total revenues were $\$ 13,653$ and total expenses were $\$ 10,585$, for a net gain of $\$ 3,069$ and an ending fund balance of $\$ 142,697$. For the same period, the Rozkuszka Scholarship Endowment Fund had a net gain of $\$ 3,726$ and an Ending Fund Balance of $\$ 118,538$. Overall, GODORT is in good fiscal health, but we need to keep a close eye on membership dues going forward and adjust our expenses and/or fund raising efforts as needed. Please see my email to the GODORT membership listserv dated June 18, 2019, for the full report. Questions via email are welcome at rebecca.hyde@slu.edu._Rebecca Hyde, GDOORT Treasurer 